\title{
Gestión DEL CONOCIMIENTO: UNA
}

\section{APUESTA DESDE LA GOBERNANZA PARA LA EDUCACIÓN EN SALUD EN EL CAUCA}

\author{
María Alejandra Cisneros-Cisneros ${ }^{*}$ \\ Luz Stella Pemberthy-Gallo* \\ Margye Katerine Chaguendo-Muñoz ${ }^{* * *}$
}

\section{Resumen}

La educación para la salud es una expresión de gobernanza del Estado hacia las comunidades y viceversa. La salud pública y sus dinámicas en el departamento del Cauca están ancladas a la diversidad étnica, cultural y social de la región. Esta cuestión hace más complejas las intervenciones y demanda de la institucionalidad estrategias que engranen y hagan sinergia con las comunidades.

El presente artículo da cuenta de una investigación que surge a partir de un vacío pragmático en la institucionalidad que no se ha podido resolver -o armonizar, si se quiereentre las intervenciones de educación en salud y la participación de las comunidades. El ejercicio investigativo se basó en una intervención social con comunidades caucanas campesinas (El Tambo), afrodescendientes (Buenos Aires) e indígenas (Resguardo de Guambia, Silvia), desarrollada mediante un enfoque de tipo cualitativo, de carácter analítico y propositivo que describe el diseño de una guía metodológica que aporte a la gobernanza en salud pública en el territorio. La intervención tiene como elemento interesante la validación de los conocimientos institucionales, saberes, sabiduría y prácticas de los pueblos, para construir una sociedad más equitativa en transición hacia la paz territorial.

\footnotetext{
* Estudiante de Maestría en Gestión de Organizaciones y Proyectos. Asesora del proceso de Gestión de la Salud Pública en la Secretaría Departamental de Salud del Cauca (Colombia). [marialejandracisneros@gmail.com], [https://orcid.org/0000-0003-3679-4917].

${ }^{*}$ Maestría en Administración de Negocios. Profesora e investigadora, Grupo de investigación GIMORC, Universidad del Cauca (Colombia). [pemberthyls@unicauca.edu.co], [https://orcid.org/0000-0002-4714-7603].

${ }^{* * *}$ Comunicadora Social. Asistente de investigación, Grupo de investigación GIMORC, Universidad del Cauca (Colombia). [cmargye@unicauca.edu.co], [https://orcid.org/0000-0002-0264-944X].

Recibido: 15 de septiembre de 2019 / Modificado: 12 de febrero de 2020 / Aceptado: 13 de febrero de 2020

Para citar este artículo

Cisneros-Cisneros, M. A., Pemberthy-Gallo, L. S. y Chaguendo-Muñoz, M. K. (2020). Gestión del conocimiento: una apuesta desde la gobernanza para la educación en salud en el Cauca. OPERA, 27, 63-89.

Dor: https://doi.org/10.18601/16578651.n27.04
} 
Palabras clave: gobernanza; gestión del conocimiento; apropiación social; educación; salud.

\section{KNOWLEDGE MANAGEMENT: A GOVERNANCE PERSPECTIVE APPROACH FOR HEALTH EDU- CATION IN CAUCA}

\section{Abstract}

Health education is an expression of state governance towards communities and vice versa. Public health and its dynamics in the department of Cauca are anchored to the ethnic, cultural and social diversity of the region. Issue that complicates the interventions and demands of the institutions and strategies that engage and make synergies with the communities.

This article gives an account of an investigation that arises from a pragmatic void from the institutional framework that could not be resolved, harmonized if desired, between health education interventions and community participation. The research exercise was based on a social intervention with peasant (El Tambo), Afro-descendant (Buenos Aires) and indigenous communities (Guambia - Silvia), developed through a qualitative, analytical and proactive approach that describes the design of a methodological guide that contributes to public health governance in the territory. Intervention that has as an interesting element the validation of the institutional knowledge, knowledge, wisdom and practices of the peoples, to build a more equitable society in transition towards territorial peace.
Key words: Governance; knowledge management; social appropriation; education; health.

\section{INTRODUCCIÓN}

Para un departamento como el Cauca, la conceptualización de la paz ha debido trasegar por todo el territorio, a través de su diversidad étnica, cultural, natural, geográfica, productiva e ideológica, por lo tanto, la paz no es un fin, sino una construcción colectiva "donde las comunidades adquieren y/o asumen la capacidad racional discursiva y de diálogo, para la superación o resolución de sus conflictos" (Cauca, 2016, p. 20).

El Plan de Desarrollo Departamental 2016 -2019, "Cauca territorio de paz", propone cinco estrategias transversales en cuatro ejes que plantean la construcción social de una paz territorial: 1) cierre de brechas sociales, económicas, territoriales y ambientales; 2) presencia integral del Estado en el territorio (PIET) (enfoque poblacional); 3) participación social y comunitaria como base para la construcción del tejido social; 4) respeto y armonización de las cosmovisiones de los grupos étnicos de la región (enfoque étnico); 5) desarrollo humano integral con sostenibilidad ambiental. Los ejes son:

- Territorio de paz y para el buen vivir.

- Generación de condiciones para la riqueza colectiva.

- Cauca cuidador de agua.

- Fortalecimiento de lo público, el buen gobierno y la participación. 
$\mathrm{Al}$ interior de estos ejes se despliegan los componentes y programas que han definido la ruta administrativa de la institución en el cuatrienio.

Las siguientes dos estrategias transversales del Plan de Desarrollo del Cauca (2016-2019): la participación social y comunitaria como base para la construcción del tejido social, el respeto y la armonización de las cosmovisiones de los grupos étnicos de la región (enfoque étnico), en el marco del eje "Territorio de paz y para el buen vivir", se empieza a vislumbrar la gestión de la salud pública entendida esta, según la Ley 1122 de 2007, como: "El conjunto de políticas que busca garantizar de manera integrada, la salud de la población por medio de acciones dirigidas tanto de manera individual como colectiva ya que sus resultados se constituyen en indicadores de las condiciones de vida, bienestar y desarrollo" (p. 12).

A través de la organización comunitaria, como primer proceso asociativo en los territorios, se debe dar la materialización de las capacidades sociales de decisión y acción política en el ámbito de la salud y en cualquier otro. Acciones como las que se describen a continuación pueden ser consideradas como estrategias para gestionar paz, y se convierten en la base para la reconstrucción del tejido social:

- Consultas previas a las comunidades en busca de su empoderamiento para que se salvaguarden los recursos públicos y medioambientales. Teniendo en cuenta que las consultas previas son un derecho que tienen todos los grupos étnicos en el momento en que se tomen medidas, realicen proyectos, obras o actividades en sus territorios con el fin de que puedan proteger su integridad cultural, social y económica, $y$, a su vez, garanticen su derecho a la participación (Rosario, s. f.). Este derecho resulta fundamental a la hora de intervenir en el territorio, por ejemplo, con los planes de ordenamiento territorial o los planes de desarrollo departamental.

- Priorización de las agendas participativas de las comunidades, de las organizaciones de la sociedad civil y otras.

- Construcción participativa de las estrategias de promoción y prevención.

- Lograr que las comunidades identifiquen sus problemas en salud y sean protagonistas en la estructuración de la solución de estos.

Es posible que este camino abra una posibilidad para lograr una mejora en los indicadores de salud en este departamento y en otras regiones a mediano y largo plazo.

Ciertamente, la construcción de la paz desde el punto de vista de la gobernanza representa un camino nuevo, con infinidad de rutas, pero que requiere, por sobre todo, salirse del esquema que comprende a la paz como un símil de la ausencia de conflicto. Es por eso que el gobierno departamental del Cauca ha tenido que empezar por proponer una ruta de fortalecimiento institucional con transparencia, eficiencia y eficacia, "que garantice derechos a las comunidades y la implementación integral de una cultura de paz, que significa riqueza colectiva, perdón, reconciliación y desarrollo integral humano, a través del diálogo, la participación, el reconocimiento y la inclusión social" (Cauca, 2016, p. 32). 
María Victoria Whittingham Munévar (2010) hace una revisión de diferentes usos y acepciones del concepto de gobernanza, así como de los proyectos de investigación e intervención orientados a promover y fortalecer la "buena gobernanza" -teoría y praxistratando de identificar los vacíos existentes. Desde la perspectiva centrada en el Estado, define a la gobernanza como:

$\mathrm{El}$ arte de liderazgo público, en el cual el actor principal es el Estado. Por lo tanto, el régimen político, la gerencia pública, y la capacidad del gobierno son elementos críticos para la buena gobernanza. Esta perspectiva enfatiza la necesidad de que existan mecanismos que dirijan, guíen a la sociedad, y adjudica este papel al Estado en forma preferencial. (p. 221)

La gobernanza debe ser armónica con los pueblos, debe ser un lenguaje que integre las diferentes formas de participación social que se gestan en las comunidades y que permita el cierre de brechas en educación, salud, vivienda, agua potable, saneamiento básico por medio de consultas previas, el empoderamiento social para la protección y salvaguarda de los recursos públicos y medioambientales, las agendas participativas como estrategias para la paz, a fin de convertirse en la base para la reconstrucción del tejido social.

Este artículo es la base de una investigación que conjuga el accionar de una institución gubernamental, la academia y las comunidades alrededor del tema de la educación para la salud y de cómo esta es una expresión de gobernanza del Estado hacia las comunidades y viceversa. En un primer momento se presentará un contexto general de la salud del departamento del Cauca (Colombia) para después explicar, a través de un enfoque metodológico, cómo se obtuvieron elementos, conclusiones y aportes que fueron el punto de partida para la construcción de un instrumento flexible que pretende armonizar las acciones en salud pública desde el gobierno departamental con las necesidades de las comunidades caucanas teniendo en cuenta un tema susceptible de exploración: la apropiación social del conocimiento en salud.

\section{PANORAMA INTERNACIONAL, REGIONAL Y LOCAL PARA LA GESTIÓN DE LA SALUD PÚBLICA}

"Asegurar una vida sana y promover el bienestar de todos en todas las edades" (PNUD, 2015) es uno de los 17 objetivos del desarrollo sostenible, que tienen como prioridades la erradicación de la pobreza, la salud, la educación, la seguridad alimentaria y la nutrición, entre otros alcances económicos, sociales y ambientales que le apuntan a sociedades más pacíficas e inclusivas.

Entre las metas del objetivo en mención están:

- Para el 2030, reducir en un tercio la mortalidad prematura por enfermedades no transmisibles mediante la prevención y el tratamiento, y promover la salud mental y el bienestar.

- Para 2030, garantizar el acceso universal a los servicios de salud sexual y reproductiva, incluidos los de planificación familiar, información y educación, y la integración de la salud reproductiva en las estrategias y los programas nacionales. 
- Para 2030, reducir la tasa mundial de mortalidad materna a menos de 70 por cada 100.000 nacidos vivos.

Dichas acciones se articulan bajo el liderazgo de los entes nacionales, departamentales y locales, y deben promover la participación responsable de todos los sectores de la comunidad a través del enfoque de derechos, diferencial, de ciclo de vida, de género, étnico y poblacional que empiezan a tenerse en cuenta en las políticas de Gobierno y en los lugares de enunciación más representativos.

Sumado a eso, las metas en salud a nivel nacional, departamental y local nos dan un contexto para pensar en la educación en salud pues están ligadas intrínsecamente a procesos de gobernanza desde las administraciones locales y regionales en primer lugar, pero también a través de la diversidad de saberes y prácticas propias de una región diversa, multicultural y pluriétnica como el Cauca.

En Colombia, durante los últimos años, el sistema de salud ha tenido considerables vacíos estructurales en temas como la accesibilidad, disponibilidad, aceptabilidad y calidad, atributos que hacen referencia al "goce efectivo del derecho fundamental a la salud", establecido en la Ley Estatutaria 1751 de 2015, por medio de la cual se regula el derecho fundamental a la salud (Congreso de la República, 2015).

Esta ley comprende a la salud como un derecho fundamental, autónomo e irrenunciable en lo individual y en lo colectivo; ha considerado elementos y principios que lo definen, entre los cuales están la accesibilidad, la universalidad, la equidad, la prevalencia de derechos, la eficiencia, la interculturalidad, la protección de pueblos y comunidades indígenas, Rrom y negras, afrocolombianas, raizales y palenqueras; frente a esto, las obligaciones del Estado se concentran en la formulación y adopción de políticas de salud para lograr el goce efectivo de este derecho. Es el Estado quien debe coordinar las acciones de todos los agentes del sistema, además de propender por la promoción de la salud, y prevención y atención de la enfermedad.

Por otra parte, el Plan Decenal de Salud Pública 2012-2021 es una política pública que surge como producto del Plan Nacional de Desarrollo 2010-2014 que busca, entre otras cosas: 1) avanzar hacia la garantía del goce efectivo del derecho a la salud; 2) mejorar las condiciones de vida que modifican la situación de salud y disminuyen la carga de la enfermedad existente; 3) mantener cero tolerancia frente a la mortalidad, la morbilidad y la discapacidad evitable.

Uno de los mayores desafíos del PDsp, es afianzar el concepto de salud como el resultado de la interacción armónica de las condiciones biológicas, mentales, sociales y culturales del individuo, así como con su entorno y con la sociedad, a fin de poder acceder a un mejor nivel de bienestar como condición esencial para la vida. (p. 28)

Este documento reúne las acciones en salud pública, y se establece como un derrotero para un periodo de diez ańos que plantea estrategias de intervención colectiva e individual, las cuales involucran tanto al sector salud como a otros sectores dentro y fuera de los servicios de salud.

Todo esto se conjuga en las intenciones del Gobierno colombiano por reconocer la salud como un derecho interdependiente y 
una dimensión central del desarrollo humano. Pero las dudas no esperan: ¿hubo una real participación en la formulación de este plan? ¿La consulta poblacional a los ciudadanos para validar el PDSP abarcó a los grupos de interés y diferenciales en las regiones?

En el 2016, el departamento del Cauca fue priorizado por el Ministerio de Salud y Protección Social como uno de los departamentos piloto, después de Guainía, para la implementación de un modelo integral de atención en salud (MIAS), que operativiza la Política de Atención Integral en Salud (PAIS) y cuyo eje central es acercar la salud a las personas que habitan territorios urbanos, rurales y rurales dispersos.

El reto y la demanda del Estado colombiano es apostarle al autocuidado, bajo una nueva premisa e interés: que las personas sean saludables. Una categoría que empieza a convertirse en el estandarte de la ley, la resolución, la política y el modelo en tanto le es más beneficioso al Estado invertir en la prevención de la enfermedad, que en la enfermedad misma.

\section{EL CONTEXTO DE SALUD EN EL CAUCA}

El departamento del Cauca se encuentra ubicado al suroccidente de Colombia y, de acuerdo al Plan de Desarrollo Departamental Cauca 2016-2019, “Territorio de Paz", está dividido en 42 municipios, organizados en siete subregiones: Piedemonte Amazónico, Centro, Macizo, Norte, Oriente, Pacífico y Sur.

Con una población total de 1.391.889 habitantes, de los cuales $26 \%$ son afrodescendientes, $24 \%$ indígenas y el $50 \%$ mestizos, el departamento del Cauca es mayoritariamente rural y rural disperso, puesto que el 39,85\% de la población se ubica en la zona urbana y el $60,15 \%$ en la zona rural. Junto a lo anterior, la Unidad para la Atención y Reparación Integral a las Víctimas (UARIV) sostiene que las décadas de guerra dejaron cerca de 367 mil víctimas registradas en el Cauca, de las cuales 235 mil viven en este momento en el territorio y que también necesitan acceder al sistema de salud (Unidad para la atención y reparación integral a las Víctimas, 2019).

Por otra parte, y como complemento a lo anterior, en el territorio convergen, junto con el Modelo Integral de Atención en Salud, otros modelos o sistemas de salud como el Sistema Indígena de Salud Propio e Intercultural (sISPI), Sistema Autónomo de Salud Intercultural del Pueblo Afrodescendiente del Cauca (SASIPAC) y un modelo de salud para el campesinado que está en construcción; lo que representa un escenario complejo a la hora de hablar de salud pública.

Estas características particulares de un departamento como el Cauca se conjugan en una población diversa que habita en diferentes subregiones, que contrastan en sus distintas dinámicas territoriales, culturales y asociativas. Tal como afirma Rincón (2009):

Cada una de estas comunidades establece con el territorio una relación distinta que reproduce y recrea el espacio habitado, en virtud de las oportunidades sociales, políticas, culturales, económicas y ambientales; entendiendo además que el espacio se ordena a partir de las relaciones de poder, del ordenamiento de las relaciones sociales de producción en el territorio, como de la incidencia de la ciencia y la tecnología, en periodos de tiempo definidos. A partir de estos aspectos, tenemos en esencia una sociedad local y regional Diversa. Así, el fundamento de la 
diversidad no es la ley, sino la sociedad en sí misma y las relaciones que se establecen entre comunidades, como con la naturaleza. (p. 60)

De tal suerte, en este territorio es indispensable hablar de gobernanza y gobernabilidad como estrategias para transformar el discurso de las instituciones, las organizaciones y la academia en acciones concretas y reales que salten de las políticas públicas, la normatividad, los enunciados, la teoría y los pactos, a la materialización de los mismos, para lograr una "sinergia amalgamada" con las características propias de las comunidades.

Lo anterior abre un panorama amplio, una fuente de oportunidades para diseñar intervenciones que reconozcan las otras visiones de salud/enfermedad, los saberes propios y, en específico, cómo dinamizar desde el ente de salud departamental los procesos locales de educación, comunicación e información que abarquen las prioridades en salud pública de cada zona, que gesten una participación activa y real de las comunidades y que evidencien que la gestión del conocimiento y la apropiación social no son asuntos propios de la academia; son atributos inherentes a las comunidades, que les sirven para comunicarse, gestionar, transformar y usar el conocimiento. En otras palabras, que reconozcan que existen diferentes formas de hacer salud a través de la cultura y viceversa (Arboleda y Daza, 2016).

\section{EL DIÁLOGO CON LAS COMUNIDADES, CLAVE EN LA COMPRENSIÓN DE LA GOBERNANZA}

Para las instituciones gubernamentales locales, regionales y nacionales, el diálogo con las comunidades no siempre resulta ser legítimo, indispensable y esencial, puesto que lo determinan como opcional. Sin embargo, para la Constitución Política de Colombia sí lo es, pues establece un principio rector cuando hace referencia a los Planes Nacionales de Desarrollo (PND), en el artículo 342, en el cual reglamenta que debe hacerse efectiva "la participación ciudadana en la discusión de los planes de desarrollo, y las modificaciones correspondientes, conforme a lo establecido en la Constitución" (Constitución Politica de Colombia, 1991). De acuerdo con el Departamento Nacional de Planeación (DNP) los PND son instrumentos formales y legales en los cuales "se señalan los propósitos y objetivos nacionales de largo plazo, las metas y prioridades de la acción estatal en el mediano plazo y las estrategias y orientaciones generales de la política económica, social y ambiental que serán adoptadas por el gobierno" (DNP, s. f.).

Algunos gobiernos deciden hacer consultas previas para la formulación de los PDN a través de encuentros subregionales, tal y como fue formulado el del departamento del Cauca, en el que participaron cerca de 6.650 personas de todas las regiones y de las comunidades organizadas. Se llevaron a cabo mesas por sectores para indagar sobre las necesidades y posibles soluciones en orden de prioridad, lo que enriqueció de manera definitiva la información diagnóstica. Este es solo un ejemplo, sin embargo, cada planeación de Gobierno debe hacerse siempre con la gente a la que van a impactar esos planes a fin de palpar la realidad económica y social de las comunidades, proyectando para ello metas coherentes con las particularidades poblacionales. 
Para el Estado y los entes territoriales, como la Gobernación del Cauca y la Secretaría de Salud Departamental, accionar la participación responsable de todos los sectores de la comunidad se convierte en un reto gigante y evidentemente necesario.

Esta investigación, precisamente, surge a partir de una inquietud, de un vacío pragmático desde la institucionalidad que no se ha podido resolver - o armonizar, si se quiere-, entre las intervenciones de educación en salud y la participación de las comunidades. Cada ańo se invierten miles de millones de pesos a través de los planes de intervenciones colectivas que se operativizan a través de las empresas sociales del Estado (ESE) y que tienen un impacto muy bajo o nulo en la salud de la población.

El ejercicio investigativo se basó en una intervención social desarrollada mediante un enfoque de tipo cualitativo, de carácter analítico y propositivo, que partió de la construcción de un estado del arte que compiló el tema de gestión del conocimiento, apropiación social y educación para la salud.

Para la construcción del estado del arte se requirió hacer una revisión documental considerable, en tanto los conceptos de gestión del conocimiento y apropiación social son categorías que no tienen un desarrollo significativo en el área de la salud (a excepción de temáticas como los sistemas de información y las plataformas de procesamiento de información para la toma de decisiones con apoyo estadístico), razón por la cual, la información recolectada y procesada da cuenta de la ausencia de bibliografía en este campo y, por tanto, esta investigación representa un aporte a la academia y al sector salud, soportado en: "un proceso sistemático y secuencial de recolección, selección, clasificación, evaluación y análisis de contenido del material empírico impreso y gráfico, físico y/o virtual que servirá de fuente teórica, conceptual y/o metodológica para una investigación científica determinada" (Rodríguez, 2013).

Como consecuencia de lo anterior, algunos conceptos clave que dan soporte a esta investigación son:

La gestión del conocimiento (GC). Esta es entendida como un proceso en el que los conocimientos tácito y explícito son tenidos en cuenta, pero que se diferencian sustancialmente, partiendo de la premisa de que el conocimiento de una organización, comunidad o institución es uno de los activos más valiosos. En este concepto se tendrá en cuenta el principio ACAT ${ }^{1}$ : Acceso (entrada o paso), Construcción (hacer algo utilizando los elementos adecuados), Almacenamiento (reunir, guardar o registrar en cantidad algo) y Transferencia (pasar o llevar algo desde un lugar a otro) del conocimiento en salud que se gestiona desde las comunidades, entidades u organizaciones participantes del proceso de la salud pública.

Apropiación social del conocimiento (ASC). Proceso que adelantan las comunidades para convertir lo externo, lo ajeno, lo occidental en algo propio, pero transformándolo, haciendo uso de códigos propios en una recepción activa. El conocimiento adquirido en salud asimilado tiene influencia directa de elementos como

1 El principio ACAT es el resultado de la interpretación y contextualización del estado del arte de esta investigación para ser aplicado en la caracterización y el diseño de la guía metodológica. 
la oralidad, la etnoculturalidad, la lengua, el lenguaje, los saberes, sentires, comprensiones e imaginarios propios, sobre una base esencial que es la conceptualización del binomio salud/ enfermedad. Se trata de la disolución de la brecha existente entre "productores" de conocimiento y "receptores" del mismo (Neüman, 2008). Tiene que ver, además, con el empoderamiento que se puede obtener por medio de ella y de cómo a través de esta, los sujetos se vinculan con la realidad. La apropiación, dice Neüman, es una "construcción teórica dentro de la modernidad" (p. 83).

Marín Agudelo (2012), en su artículo: "Apropiación social del conocimiento: una nueva dimensión de los archivos", hace una exposición importante acerca de la preocupación que se ha despertado por el conocimiento en comunidades científicas, gobiernos y medios de comunicación, como un compromiso de la comunidad para avanzar.

La apropiación social del conocimiento se entiende como un proceso que implica, por un lado, la disposición de los conocimientos científicos y tecnológicos en un escenario y lenguaje comunes para la sociedad; y por otro, que el ser humano hizo suyos tales conocimientos como elementos útiles y necesarios para su beneficio y provecho. Apropiación social del conocimiento, desde la óptica de la sociedad del conocimiento, significa, entonces, la democratización del acceso y uso del conocimiento científico y tecnológico, como estrategia para su adecuada transmisión y aprovechamiento entre los distintos actores sociales, que derivará en el mejoramiento de la calidad de vida de las comunidades y sus integrantes. (p. 56)

Esta propuesta se apoya en lo expuesto por Mejía y Salgado (2009) en la tarea por seleccionar, procesar y transformar los datos en conocimiento. En esa necesidad de comprender cómo, a través de la apropiación social, las personas transforman los datos en conocimiento como resultado de un proceso de reflexión y síntesis de estas. No se trata de un proceso lineal, sino dinámico, sistémico y complejo, e incluso cíclico.

TABLA 1. DE LOS DATOS A LA SABIDURÍA

\begin{tabular}{|c|c|c|c|}
\hline Datos & Información & Conocimiento & Sabiduría \\
\hline $\begin{array}{c}\text { Sin } \\
\text { propósito }\end{array}$ & $\begin{array}{l}\text { Interpre- } \\
\text { tación de } \\
\text { asociaciones }\end{array}$ & $\begin{array}{l}\text { Conciencia de } \\
\text { patrones }\end{array}$ & $\begin{array}{l}\text { Compren- } \\
\text { sión de } \\
\text { principio }\end{array}$ \\
\hline
\end{tabular}

Fuente: tomado de Mejía y Salgado (2009).

Es importante anotar que el entendimiento de la fase sabiduría es una categoría esencial para esta investigación. Las autoras hacen una aproximación de esta transición, sin embargo, la última pieza es el engranaje perfecto para la comprensión de la gestión del conocimiento y se convierte en un insumo transversal para la propuesta de la guía metodológica.

Macías Chapula (2009) evidencia el comportamiento de los flujos de comunicación científica en un sistema de salud fragmentado, verticalizado y desvinculado de las dinámicas poblacionales y territoriales, que tiene serias dificultades con la construcción de contenidos sin consensuar con los usuarios reales y potenciales a quienes finalmente les llegarían tanto el servicio de salud como los programas de promoción y prevención que abandera la salud pública. Explica su modelo a través de un triángulo, donde el ápice corresponde a los generadores del conocimiento; en la parte intermedia del triángulo se ubican los trabajadores de la salud, y en la base de la pirámide, la población general. Se presenta, entonces, que los "flujos de información y del conocimiento son abundantes pero en un sentido horizontal 
entre los actores de la punta del triángulo; menos fluida en la parte intermedia del triángulo y muy débil, en la base del mismo" (p. 33). Concluye que los flujos del conocimiento de manera vertical en los tres niveles es inexistente (figura 1).

FIGURA 1. MODELO DE DESARROLLO DE LOS FLUJOS DE COMUNICACIÓN CIENTÍFICA EN UN SISTEMA DE SALUD

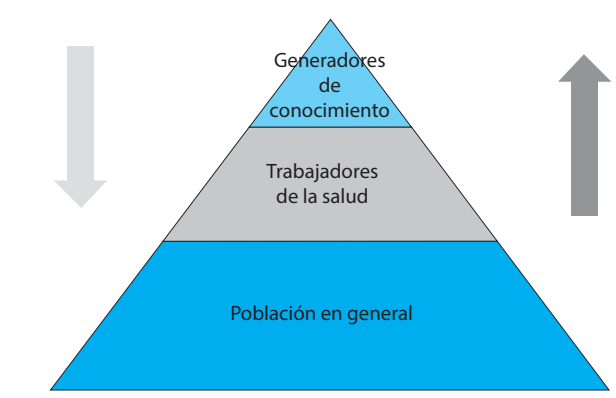

Fuente: elaboración propia con base en Macías (2009).

\section{ELTRINOMIO EDUCACIÓN-COMUNICACIÓN- SALUD}

La educación y la salud iniciaron una relación estrecha, que con la generalización de la educación universal, obligatoria, la extensión de los sistemas sanitarios en Occidente ${ }^{2}$, los dispositivos educativos y asistenciales fueron alcanzando a gran parte de la población. Comelles y Perdiguero (2017) afirman que:

2 Concepción que se origina en la diferenciación que se hace de dos regiones geográficas, Oriente/Occidente, en aspectos culturales como la lengua, la escritura, la religión y las tradiciones.
Con anterioridad, los médicos se dirigieron a la población para aconsejarla o imponerle determinados modos de ver la salud y la enfermedad en el contexto de la relación médico paciente o mediante el empleo, en un primer momento, de la comunicación escrita, posteriormente de los medios de comunicación de masas. (p. 7)

El trinomio educación-comunicación-salud requiere de una participación responsable en la divulgación de productos y servicios relacionados con la salud. Con el advenimiento de la era digital, el internet y las nuevas tecnologías, esta relación (el trinomio) se entrelaza de manera estrecha y repercute directamente en el modo de concebir la salud por parte de las personas $y$, por otra parte $-y$ no menos importante-, la manera como las autoridades en salud buscan cuidar la salud de las personas a través de brindar una información en salud clara, eficaz, que oriente, persuada, recomiende y prevenga dańos futuros en la salud de las personas.

El desarrollo tecnológico en la comunicación y gestión del conocimiento ha tenido un impacto positivo en temas de salud puesto que ha contribuido al despliegue de diferentes estrategias difundidas con la ayuda de herramientas variadas. Esto gracias a la capacidad que tienen las TIC para "influir sobre importantes determinantes generales de la salud, como las relaciones sociales, los procesos culturales y otros aspectos fuertemente relacionados con el bienestar físico, mental y social" (Castiel y Sanz, 2010, p. 29). Las TIC, además, permiten ampliar el acceso de información a las comunidades, gracias a los distintos medios y herramientas tecnológicas, lo que genera que se puedan ejercer acciones colectivas en los temas de salud entre todos los actores vinculados. 
Aunque "el acceso a la información en salud está hoy enormemente facilitado por las nuevas TIC, particularmente Internet, las cuales pueden ejercer gran influencia sobre la situación de salud y, en particular, sobre las inequidades en salud" (Castiel y Sanz, 2010, p. 29), es necesario que se resuelvan las inequidades de acceso a las nuevas tecnologías, ya que así se podría aprovechar de una mejor manera este recurso y se podría promover, por medio de sus herramientas, el acceso a la información en salud, a fin de actuar en la expansión del conocimiento y en el incremento del margen de acción para intervenir de manera positiva en la salud de todas las comunidades.

Por su parte, Llanusa, Rojo, Caraballoso, Capote y Pérez (2005) afirman que:

La investigación, desarrollo y aplicación de soluciones innovadoras y la capacidad de gestión para organizar sistemas y servicios de salud tienen una aliada excepcional en estas tecnologías, ya que potencian la gestión de la información y el conocimiento y la retroalimentación de los usuarios finales a quienes están destinados estos esfuerzos. (pp. 227-228)

Un ejemplo de ello es la "telemedicina”, aquella prestación de servicios clínicos de salud a distancia, entre profesionales de la salud y pacientes, a través de distintas herramientas tecnológicas y de comunicación. La telemedicina, entre otros beneficios, brinda la posibilidad de ofrecer una mejor cobertura de los servicios, e intercambiar con mayor efectividad información administrativa y clínica (ops, 2000).

Pese a que la comunicación y los medios de comunicación se constituyeron sobre un modelo conductista, es necesario comenzar a pensarlos desde una perspectiva que contem- ple la complejidad de las prácticas sociales y comunicativas que faciliten conocer los participantes y sus verdaderas necesidades (Pemberthy, Cruz y Viveros, 2019), "como también para construir diálogo con la ciudadanía” (Falla, Hermelin y Aguirre, 2016, p. 59).

Mario Kaplún, en su libro Una pedagogía de la educación, anuncia que la verdadera comunicación es aquella en la que dos o más seres intercambian sentidos: "Es a través de ese proceso de intercambio como los seres humanos establecen relaciones entre sí y pasan de la existencia individual aislada a la existencia social comunitaria” (1998, p. 58).

Además, invita a ver la educación como

... un proceso permanente, en que el sujeto va descubriendo, elaborando, reinventando, haciendo suyo el conocimiento. Un proceso de acción-reflexión-acción que él hace desde su realidad, desde su experiencia, desde su práctica social, junto con los demás. Y en el que hay también quien está ahí -el "educador/educando"- pero ya no como el que enseña y dirige, sino para acompañar al otro, para estimular ese proceso de análisis y reflexión, para facilitárselo; para aprender junto a él y de él; para construir juntos. (p. 45)

\section{Participación social en salud}

Retomando un concepto de la Organización Mundial de la Salud (oms), "la participación significa que la persona, el grupo o la comunidad trabajan activamente, con los agentes de salud y otros, para resolver sus propios problemas. La participación es necesaria en todas las fases, desde la identificación de los problemas hasta su solución" (1989, p. 32).

¿Y por qué es necesaria la participación? Porque al participar, las personas estarán más interesadas y comprometidas a tomar las me- 
didas necesarias para mejorar su salud, y en adquirir conocimientos para participar activamente desde la identificación de problemas hasta la solución de los mismos. Es un concepto también basado en los postulados consignados en la Resolución 2063 de 2017, por la cual se adopta la Política de Participación Social en Salud (ppss) (Ministerio de Salud y Protección Social, 2017) y en la que se reconoce a la participación como derecho y práctica social.

Uno de los logros más interesantes de esta investigación fue la caracterización de las dinámicas de gestión de conocimiento para la apropiación social en las intervenciones de información, educación y comunicación desde los actores del Sistema General de Seguridad Social en Salud pública de la región (Secretaría Departamental de Salud del Cauca, empresas sociales del Estado, secretarías de salud municipales) y las comunidades caucanas. Se trató de un trabajo de campo para lograr un acercamiento a los actores, principalmente a un grupo particular de personas que representan la diversidad de la región desde el campesinado, la población afrodescendiente e indígena.

Para el alcance de este objetivo fue importante aterrizar el concepto de Gestión del Conocimiento a las dinámicas de salud pública de las comunidades caucanas, lo que implicó adelantar un análisis de la apropiación del conocimiento que se gesta en sus comprensiones de salud/enfermedad/cuidado, reconocer los procesos de información, comunicación y educación para la salud que se implementan desde la institucionalidad y las comunidades, y lograr así, emprender un camino hacia una descripción cualitativa con la identificación y organización de datos, experiencias y conoci- mientos. "El conocimiento se fortalece cuando las decisiones que se toman son concordantes con las informaciones originadas en grupos de personas; de allí que es primordial identificar la información coherente con el entorno" (Martínez, 2007, p. 103).

El aporte más valioso de esta caracterización fue el trabajo en campo para recolectar la información necesaria, puesto que es imposible hablar de un contexto de diversidad sin tener en cuenta precisamente ese elemento transversal en esta investigación. A través de entrevistas a profundidad y grupos focales, se consultó a población campesina del municipio de El Tambo, parteras afrodescendientes del municipio de Buenos Aires y a un indígena perteneciente al resguardo de Guambía del municipio de Silvia.

La información obtenida a través de las entrevistas y los grupos focales se sistematizó en un documento en Excel con las categorías de análisis definidas para análisis, consulta y revisión. Esta sistematización se hizo de manera exhaustiva con el propósito de realizar una construcción de memoria como lo señala Mariño (2011), además como resultado del diálogo sostenido con todos los actores participantes, con el fin de darle soporte a las propuestas, socializar los resultados y devolver este conocimiento a la comunidad a través de una herramienta que dé respuesta a sus necesidades.

Construir una memoria integral critica como resultado del diálogo entre los diferentes actores, que incorpore elementos analíticos y socio afectivos, buscando la comprensión del proceso y sus resultados, con el fin de contribuir tanto a la producción como a la socialización y devolución de conocimiento y a la cualificación de los trabajos. (p. 10) 
Un elemento importante por mencionar es que durante la recolección de información en campo se consideraron elementos de la propuesta metodológica de Victoria, Pemberthy y Maya (2007) que se apoya en una estrategia de comunicación; asimismo, los grupos focales permitieron, por su versatilidad, recolectar datos acerca de conocimientos, actitudes y prácticas sociales que difícilmente hubieran sido obtenidas con entrevistas personalizadas y con preguntas concretas. "Es así que, el hecho de que los participantes compartan experiencias en el interior del grupo, hace del grupo focal una forma más efectiva, profunda y significativa de obtener información" (Escobar y Jiménez, 2017, p. 62).

Con el propósito de identificar, describir y analizar las dinámicas de gestión del conocimiento de los municipios priorizados, así como sus procesos de apropiación social a través de las intervenciones de información, educación y comunicación que diseñan, desarrollan e implementan en los territorios, se definieron tres categorías de análisis que se abordarán a continuación.

\section{Análisis de la gestión del conocimiento en salud}

A esta categoría le es encomendada la tarea de analizar la manera como el conocimiento en salud se ha convertido en una herramienta de aprendizaje, un recurso para la toma de decisiones, de educación útil que aporta valor y genera transformación dentro de las entidades públicas, organizaciones o comunidades. Para abordarla se tuvieron en cuenta los siguientes campos de análisis que se resumen en el principio ACAT, ya mencionado.
Entre los principales hallazgos en el análisis de este aparte vale la pena mencionar la caracterización que se hizo a nivel comunitario respecto al principio ACAT:

- Fuera de la información institucional a la que acceden de manera verticalizada, a veces hasta impuesta desde el nivel nacional, el acceso de las comunidades al conocimiento en salud se basa en la ancestralidad, el conocimiento del cuerpo, el ambiente, el territorio y los recursos naturales que tienen a su alcance y que constituyen su cultura, sus imaginarios individuales/colectivos, su relacionamiento con la naturaleza y el desarrollo de su bienestar integral. Su cosmovisión le apunta a comprender la salud como un estado de armonía con el territorio (cuerpo-naturaleza-espiritualidad).

- La construcción se hace a partir del diálogo intergeneracional propio de cada comunidad, de la observación de quienes están dispuestos a aprender de distintos temas de salud y de la práctica de los conocimientos transmitidos por ese diálogo, dentro de su propia comunidad.

La construcción se da en una red con muchos nodos que son intersección, conexión o unión de varios elementos que confluyen, se crean, se transforman y legitiman a través de los usos, las costumbres, los saberes y los sentir-pensares de los pueblos.

- Respecto al almacenamiento del conocimiento, las comunidades tienen una debilidad con respecto a la conservación de las tradiciones, la lengua y sus ritua- 
les. Si bien la oralidad y la memoria son sus principales recursos, hay una clara dificultad para la recuperación, sistematización y documentación de la memoria colectiva. En algunos casos los y las mayo$\mathrm{ras}^{3}$ guardan la información celosamente y prefieren almacenarla en la memoria y transferirla a través de la oralidad.

- La transferencia tiene que ver con un conocimiento empírico, no científico, adquirido por la experiencia, el contacto directo con la realidad y la percepción que se hace de ella. Un ejemplo de esto es lo que aseguran las parteras de Buenos Aires: "Yo aprendí porque la abuela mía, la mamá de mi papá era partera, de ahí aprendió mi mamá, cuando uno estaba pequeño, no lo dejaban entrar, pero ya después cuando uno iba a ver cómo ella hacía... allá yo aprendí... y así fui saliendo". (Carabalí, O., 2017)

"Yo aprendí de mi abuela, y ya mi abuela sabía, mi mamá aprendió de ella, porque mi abuela siempre decía, vea aprenda para que cuando yo me muera ustedes recuerden algo". (Carabalí, T., 2017)

La transferencia se da de diferentes maneras: lineal, escalonada, horizontal, vertical y diversificada de padres a hijos, entre hermanos, entre familiares, vecinos y grupal. Se da generalmen-

3 Un mayor o una mayora en las comunidades indígenas es un ser apreciado y valorado dentro y fuera de la comunidad. Es una persona presente, activa y esencial en la vida comunitaria, en la toma de decisiones a nivel sociocultural, puesto que son portadores de conocimientos acerca del territorio, de la naturaleza, de la historia, del cuerpo y hasta de los aspectos más profundos del ser. te en espacios familiares y comunitarios a través de la ritualidad, entendida como la práctica de acciones que tienen un valor y significado simbólico obtenido con el tiempo, las generaciones y la experiencia que se gestan alrededor de creencias, prácticas, memoria histórica de la comunidad, saberes, sentires y pensares.

La lengua es un elemento esencial en la transferencia de este conocimiento puesto que, como plantean Chica et al. (2019) en una serie documental que narra la defensa de las lenguas indígenas:

Las lenguas nativas no solo constituyen "parte integrante del patrimonio cultural inmaterial de los pueblos que las hablan", como lo enuncia la Ley 1381 de 2010. Sino que son la base estructural del pensamiento de los mismos, de sus tradiciones y cultura en general, a través de la cual mantienen su identidad.

\section{Análisis de la apropiación social del conocimiento en salud}

Esta categoría, si bien es cierto está íntimamente ligada con la anterior, tiene que ver con un componente distintivo: el proceso que adelantan las comunidades para convertir lo externo, lo ajeno, lo occidental en algo propio, pero transformándolo, haciendo uso de códigos propios en una recepción activa. Este análisis permitió evidenciar que el conocimiento adquirido en salud se ha asimilado a partir de la influencia directa de elementos como la oralidad, la etnoculturalidad, el lenguaje, los saberes, los sentires, las comprensiones y los imaginarios propios, sobre una base esencial que es la conceptualización del binomio salud/ enfermedad.

La oMs desarrolló un concepto más amplio, el binomio salud/enfermedad no tiene las 
mismas concepciones entre las comunidades caucanas. Coexiste una apropiación social de este concepto bastante amplio, diverso e interesante, que no se puede encasillar en un solo y único punto de vista. Por ejemplo, para un campesino del municipio de El Tambo, el concepto de enfermedad es no poder labrar la tierra (Tambo, 2017); para una partera afrodescendiente del municipio de Buenos Aires la enfermedad es no poder participar de sus actividades sociales y culturales (Buenos Aires, 2017); mientras que para un indígena del resguardo de Guambia, en el municipio de Silvia, es estar en desarmonía con el territorio, un desequilibrio comunitario (Mamadominga, 2018).

\section{INFORMACIÓN, COMUNICACIÓN Y EDUCACIÓN PARA LA SALUD DESDE LA INSTITUCIONALIDAD}

Este análisis aportó una descripción con una postura crítica frente a las acciones adelantadas por el sector público (MinSalud, Secretaría de Salud del Cauca, Ese Cauca, secretarías de salud municipales) para el suministro de información y construcción de conocimiento y aprendizaje sobre aspectos relacionados con la salud pública, que contribuya a la construcción de elementos que propicien la toma de decisiones en el área, y, de esa manera, se logre el cuidado efectivo de la salud de las personas a través de la promoción y la prevención. "No basta con aumentar la comunicación de cómo combatir el mal y alertar a las comunidades, sino de consolidar información acorde a las realidades de las regiones” (Martínez, 2007, p. 107).
Una conclusión de esta caracterización fue evidenciar que el primer desafío para las organizaciones gubernamentales es lograr que las comunidades incentiven su autonomía y la conviertan en la punta de lanza para el cuidado de la salud de sus pueblos. La Secretaría de Salud del Departamento debe insistir, promover, alentar y respaldar procesos de educación, comunicación e información más autónomos, más participativos, que permitan el reconocimiento de cada persona en su ámbito y territorio en el que se desarrolla y que, a la par, permita la expresión de los pueblos a través de su lengua, el folclor, la música, el arte y la comunicación.

\section{UNA HOJA DE RUTA HACIA LA EDUCACIÓN PARA LA SALUD PARTICIPATIVA}

La caracterización de las dinámicas de gestión de conocimiento para la apropiación social en las intervenciones de información, educación y comunicación son el elemento clave para el alcance del objetivo de la construcción de una guía metodológica que busca tres finalidades: 1) el despertar de la conciencia del personal de salud que labora en campo para que adelanten procesos de verdadera construcción y participación comunitaria; 2) el reconocimiento de las formas de gestionar y apropiar el conocimiento en salud de los pueblos, y 3) tener una hoja de ruta clara que le aporte a una inversión concienzuda, planificada y participativa de los recursos destinados a la educación para la salud en los territorios, de acuerdo con las necesidades de las personas. 
¿Por qué proponer una guía metodológica para orientar los procesos de educación, comunicación e información en salud que se lideran desde la Secretaría de Salud del Cauca? ¿Quiénes lo requieren? ¿Para qué? ¿Qué utilidad tendrá?

Estos y otros interrogantes surgieron de la experiencia de una de las investigadoras que ha tenido contacto con el sector salud estatal y la comunidad. Surgieron al evidenciar la confusión que rodea los conceptos de educación, comunicación e información en la ejecución de los Planes de Intervenciones Colectivas (PIC), en la instrumentalización en la que han caído los medios de comunicación tradicionales y los canales o medios físicos a través de los cuales se transmite un mensaje en un papel o en una lona, desconociendo las infinidades pedagógicas, educativas y comunicacionales existentes $y$, por sobre todo, en la incapacidad que tiene la institucionalidad y la misma comunidad de verse a sí mismos como educadores, comunicadores, transformadores y protagonistas en la gestión de su salud.

Partir de la premisa de que el conocimiento de una organización, comunidad o institución es uno de los activos más valiosos es uno de los enunciados que respalda el enfoque de GC para la ASC en el que se basa esta propuesta. Conocimiento que nace de las personas y su relación con el entorno; partiendo de ese hecho, son las personas las piezas clave más importantes en esta dinámica, de quienes debe surgir el proceso educativo, comunicativo e informativo; ellas son la fuente, el cúmulo de conocimientos, las generadoras de ideas, quienes resuelven problemas y toman decisiones de acuerdo con sus experiencias, vínculos con el territorio y el cuerpo; en ese sentido, tal y como lo exponen Mejía y Salgado (2009):

El conocimiento tácito es valioso entre tanto refiere al saber, resultado de la experiencia de las personas, difícil de codificar y que se transmite con el ejemplo, la demostración; mientras que el conocimiento estructurado y codificado, refieren al conocimiento explícito difícilmente puede ser reducido en su totalidad en conocimiento explícito. (p. 28)

Con los insumos obtenidos durante el trabajo de campo, de los grupos focales y de acuerdo con las necesidades manifestadas, se concluyó que se requiere de una herramienta metodológica que recoja los vacíos conceptuales, técnicos y administrativos que se presentan en la operativización de la promoción de la salud y en la que se consignen de manera general los lineamientos y las consideraciones para invertir acciones y recursos que le den respuesta a las prioridades en salud que tienen los colectivos. Junto a ello, esta investigación conjugada en tres objetivos es un aporte académico importante desde el enfoque etnológico (Bojacá, 2005), pues se hace un acercamiento a tres grupos de comunidades caucanas muy diferentes entre sí, para apreciar el comportamiento y la cotidianidad en ellas, con lo que se logra obtener información valiosa, que se sistematiza, se procesa y se entrega a una institución pública que, al estar al servicio de la sociedad, debería trabajar aunadamente con la academia y la empresa para lograr un proceso de innovación dinámico soportado en las acciones de la cuádruple hélice (Pemberthy y Plazas, 2014). Lo anterior, a fin de enfrentar de manera conjunta los continuos desafíos que, para este caso, están enfocados en la salud pública (Duarte, Rojas, Dorinngo, Arias, Vega y Rolón, 2015). 
La guía metodológica es un instrumento flexible donde prima un proceso educativo, comunicativo e informativo transformador, inclusivo, apegado a las necesidades de las personas y el territorio, $y$, a la vez, que genere autonomía, que incluya expresiones culturales y que deje una capacidad instalada en los municipios para fortalecer sus dinámicas; comprende una hoja de ruta que contiene un paso a paso desde la planeación hasta la evaluación de estas intervenciones, que se desarrollan en el marco de los PIC, teniendo en cuenta las prioridades, dimensiones o programas en salud pública. "Los procesos participativos permiten profundizar en el conocimiento sobre cómo piensa el individuo o el grupo, cuál es su manera de explicarse la realidad y cómo construye conocimientos de esta" (Valadez et al., 2016, p. 58).

Los PIC son definidos y financiados por la entidad territorial y operativizados por las ESE; en el caso de que ellas no cuenten con los servicios o la capacidad, pueden ser ejecutados por una Institución Prestadora de Salud (IPS) o cualquier otro operador con experiencia suficiente en la ejecución de estos planes. El PIC puede ser departamental o municipal y su finalidad, según el Ministerio de Salud y Protección Social (2017) es:

Desarrollar las capacidades de las personas, familias, comunidades y organizaciones para comprender las situaciones de salud-enfermedad que viven; construir, apropiar e implementar los saberes necesarios para aportar al mejoramiento de las condiciones de calidad de vida y salud (tanto individuales como colectivas, en sus contextos específicos) y contribuir, como agentes sociales de cambio, en la garantía del derecho a la salud. (p. 33)
Las intervenciones colectivas se refieren a las actividades para la promoción de la salud y la gestión del riesgo dirigidas a grupos poblacionales a lo largo del curso de la vida, de acuerdo con las prioridades de salud de cada territorio. Estas intervenciones son plasmadas en un plan que debe ajustarse a las necesidades territoriales, para lo cual la nación asigna recursos. Los temas o las prioridades en general están determinadas por el (MinSalud, 2013) en el documento del Plan Decenal de Salud Pública 2012-2021 y son: 1) Salud ambiental, 2) Vida saludable y condiciones no transmisibles, 3) Convivencia social y salud mental, 4) Seguridad alimentaria y nutricional, 5) Sexualidad, derechos sexuales y reproductivos, 6) Vida saludable y enfermedades no trasmisibles, 7) Salud Pública en emergencias y desastres, 8) Salud y ámbito laboral, 9) Gestión diferencial de poblaciones vulnerables y 10) Fortalecimiento de la autoridad sanitaria para la gestión de la salud.

La Resolución 518 del 2015 define las disposiciones y establece las directrices para la ejecución, el seguimiento y la evaluación de los PIC y está orientado por los siguientes principios: estatal, gratuidad, territorialidad. "Deben potenciar la salud de las personas, familias y comunidades, evitando el daño o mitigando sus consecuencias, sin que con su ejecución se ponga en riesgo la salud y la vida de las mismas" (MinSalud, 2015, p. 8).

Esta propuesta se basa en la premisa de fortalecer el autocuidado en las personas, haciéndolas partícipes y protagonistas del cuidado de su salud con la incorporación de prácticas protectoras de vida en los futuros 
momentos del curso de vida, y así prepararse para evitar posibles daños a la salud, reconocer signos de alarma y controlar los factores de riesgo que favorecen el surgimiento de ciertas enfermedades.

A continuación, se describirán de manera resumida los cinco componentes que deben hacer parte del proceso de diseño o formulación de las intervenciones de educación, comunicación para la salud (ECpS) e información en salud (IeS), conceptos retomados de la Resolución 518 de 2015, de acuerdo con lo que definió el Ministerio de Salud y Protección Social.

\section{Componente Contextualización}

Este es el primer paso y consiste en definir el conjunto de circunstancias que rodearán el trabajo por realizar. Se inicia con la definición de la prioridad en salud pública, programa o dimensión sobre la cual se trabajarán los procesos de ECpS e IeS. Para iniciar se deberá definir un punto de partida (A) de la situación actual en la que se encuentra el municipio, lo que requiere la revisión de: a) el documento de Análisis de Situación de Salud ${ }^{4}$ (asis) del municipio donde se está haciendo la intervención; b) los procesos adelantados respecto a $\mathrm{ECpS}$ e IeS o experiencias exitosas en el tema que puedan retomarse; c) el documento PASE a la Equidad

4 AsIs es un conjunto de conceptos, métodos y actividades para la medición y el monitoreo del proceso salud-enfermedad-servicios, utilizando diferentes metodologías que permiten el análisis estratégico y la síntesis de información con el fin de facilitar la gestión en salud de manera propositiva, oportuna y participativa, en colaboración con diversos actores y sectores sociales (ops, 2012). con el cual cada entidad territorial elaboró su plan territorial de salud y que aporta información clave sobre las situaciones de salud que se van a intervenir. Es esencial la elaboración de un mapeo de actores para identificar otros actores a fin de articular los procesos y evitar la repetición de acciones en terreno.

\section{Componente Justificación y delimitación}

Consiste en la exposición breve, concisa y completa de las razones por las cuales se debe realizar dicha intervención, definir un propósito y explicar por qué es conveniente o cuáles son los beneficios que se esperan. Es importante definir y justificar el tipo de intervención que se llevará a cabo, si se trata de ECpS o de IeS, esta decisión depende de lo especificado en la formulación del PIC departamental o municipal, de los recursos asignados y, en la mayoría de los casos, de lo que realmente requiere la comunidad que se va a intervenir. La delimitación tiene que ver con la formulación de un objetivo general o de objetivos específicos que orienten la meta.

\section{Componente Metodológico}

Para el desarrollo de este apartado se retomaron en gran parte las orientaciones dadas por el Ministerio de Salud y Protección Social respecto a las intervenciones de ECpS e IeS consignadas en el anexo técnico de la Resolución 518 de 2015 y que brindan una buena descripción y alcance de cada una de las intervenciones.

El aporte de esta guía metodológica es precisamente cómo llevar a cabo cada intervención y qué elementos tener en cuenta a la 
hora de trabajar con la comunidad, por lo cual se ha definido que el concepto de educación popular es el lineamiento transversal para estas intervenciones y que debe tener en cuenta lo siguiente:

- Se trata de una educación alejada del tipo de educación vertical y autoritaria.

- Es una educación No paternalista, mucho menos asistencialista.

- $\quad$ No se trata de una instrucción, sino de una construcción conjunta y horizontal.

- Es una educación alejada de la educación "bancaria" como la define Paulo Freire (1969):

La educación bancaria dicta ideas. No hay intercambio de ideas. No debate o discute temas. Trabaja sobre el educando. Le impone una orden que él no comparte, a la cual solo se acomoda. No le ofrece medios para pensar auténticamente, porque al recibir las fórmulas dadas, simplemente las guarda. No las incorpora, porque la incorporación es el resultado de la búsqueda, de algo que exige de parte de quien lo intenta, un esfuerzo de re-creación, de invención. (p. 16)

La tabla 2 explica brevemente la diferencia sustancial que existe entre una intervención de información en salud, entendida esta como un proceso más sencillo para orientar, persuadir e informar a la población sobre un tema en salud, y una intervención de educación y comunicación para la salud que tiene que ver más con el diálogo de saberes, la investigación-acción participativa y la resolución de problemáticas de salud con la intervención indispensable de la comunidad. Las dos -ECpS e IeS- tienen una finalidad diferente, pero en las dos se debe dar la participación comunitaria como elemento esencial en la construcción de estrategias de promoción y prevención.

\section{TABLA 2. DIFERENCIACIÓN PARA ABORDAR LA METODOLOGÍA}

\begin{tabular}{|c|c|}
\hline Intervenciones de Información en Salud - leS & Intervenciones de Educación y Comunicación para la salud - EcpS \\
\hline Según lo establecido por el Ministerio de Salud y Protección Social en la Reso- & Estas intervenciones pueden iniciarse como un proceso de información en salud \\
\hline lución 518 de 2015, la información en salud es definida como: & pero más exhaustivo, con una planeación más estructurada y que generalmente \\
\hline Acciones de producción, organización y difusión de un conjunto de datos & termina con la formación de agentes comunitarios multiplicadores del proceso \\
\hline o mensajes para orientar, advertir, anunciar o recomendar a los individuos, & educativo. El Ministerio de Salud y Protección Social (2015) las ha definido como: \\
\hline familias, comunidades, organizaciones y redes, así como a los actores del & Proceso de construcción de conocimiento y aprendizaje mediante el diálo- \\
\hline Sistema General de Seguridad Social en Salud y otros sectores sobre aspectos & go de saberes, orientado al desarrollo y fortalecimiento del potencial y las \\
\hline relacionados con la salud pública, que contribuya a la construcción de ele- & capacidades de las personas, las familias, las comunidades, las organizacio- \\
\hline \multirow[t]{2}{*}{ mentos que propicien la toma de decisiones en salud. (MinSalud, 2015, p. 21) } & nes y redes para la promoción de la salud individual y colectiva, la gestión \\
\hline & del riesgo y la transformación positiva de los diferentes entornos. (p. 22) \\
\hline
\end{tabular}

Fuente: Ministerio de Salud y Protección Social, Resolución 518 de 2015.

\section{Componente de Evaluación y seguimiento}

Con este componente se sugiere la elaboración de indicadores (de resultado y eficacia e impacto) que tracen el camino por transitar, que permitan mejorar la gestión y sean unas herramientas que faciliten la evaluación y la rendición de cuentas de los recursos invertidos. Según lo que establece la Guía para el diseño, construcción e interpretación de indicadores del Departamento Administrativo Nacional de Estadística (DANE), un indicador es: 
Una expresión cualitativa o cuantitativa observable que permite describir características, comportamientos o fenómenos de la realidad a través de la evolución de una variable o el establecimiento de una relación entre variables, la que comparada con periodos anteriores o bien frente a una meta o compromiso, permite evaluar el desempeño y su evolución en el tiempo. (DANE, s. f., p. 13)

\section{Componente Sistematización}

Este es el último componente, pero no por ello el menos importante. Se debe documentar el proceso a través de documentos en Office y material multimedia que den cuenta de su construcción, implementación y evaluación. Según el Ministerio de Salud y Protección Social (2016), para sistematizar:

Es necesario definir qué es lo que interesa indagar con respecto a la experiencia, por ejemplo: ¿Qué prácticas se presentan en territorios?, ¿qué interpretaciones tienen en los territorios sobre las mismas?, ¿cómo le aporta una determinada experiencia educativa y comunicativa a un proceso de construcción de prácticas de promoción de la salud? (p. 12)

Esta sistematización la realizará el o los facilitadores que estuvieron en todo el proceso. No necesariamente debe ser rigurosa, pero sí debe condensar los momentos más importantes, aquellos en los cuales se hizo una construcción conjunta para definir el tipo de intervención.

Es muy importante consultar el método para sistematizar a la población objetivo, es probable que se necesite negociar con ellos en el caso que se prefiera la oralidad antes que plasmar en un documento toda la experiencia. Es importante aclarar que cuando se sistema- tiza se está construyendo conocimiento para la comunidad, en beneficio de ella y su salud. Se sugiere que se realice a partir del principio ACAT (acceso, construcción, almacenamiento y transferencia), que se trabajó a lo largo de toda esta investigación y que establece una manera de gestionar el conocimiento para tener claridad acerca de cómo se accede a él, cómo se construye, cómo se almacena y se transfiere.

\section{RESUMEN DE LA GUÍA METODOLÓGICA}

El triángulo que se presenta en la figura 2 tiene dos significados, el primero se refiere a la unión de todos los componentes alrededor de la participación social, la GC, el principio ACAT y la apropiación social como los elementos trazadores de toda la propuesta; el segundo significado tiene que ver con la propuesta de una nueva manera de concebir la educación en salud como un proceso horizontal, donde los *flujos de comunicación científica y no científica se deben representar en un triángulo invertido, donde la base corresponde a los generadores del conocimiento, es decir, la comunidad y la participación social como la posibilidad de devolverles ese poder de ser, sentir, pensar y construir; en la parte intermedia del triángulo se ubican los trabajadores de la salud y otros actores participantes, y en el ápice de la pirámide, los entes territoriales, locales y el Ministerio de Salud y Protección Social como actores facilitadores, interlocutores y observadores de estos procesos. 
FIGURA 2. RESUMEN GUÍA METODOLÓGICA PARA LA IMPLEMENTACIÓN DE INTERVENCIONES DE ECPS E IES

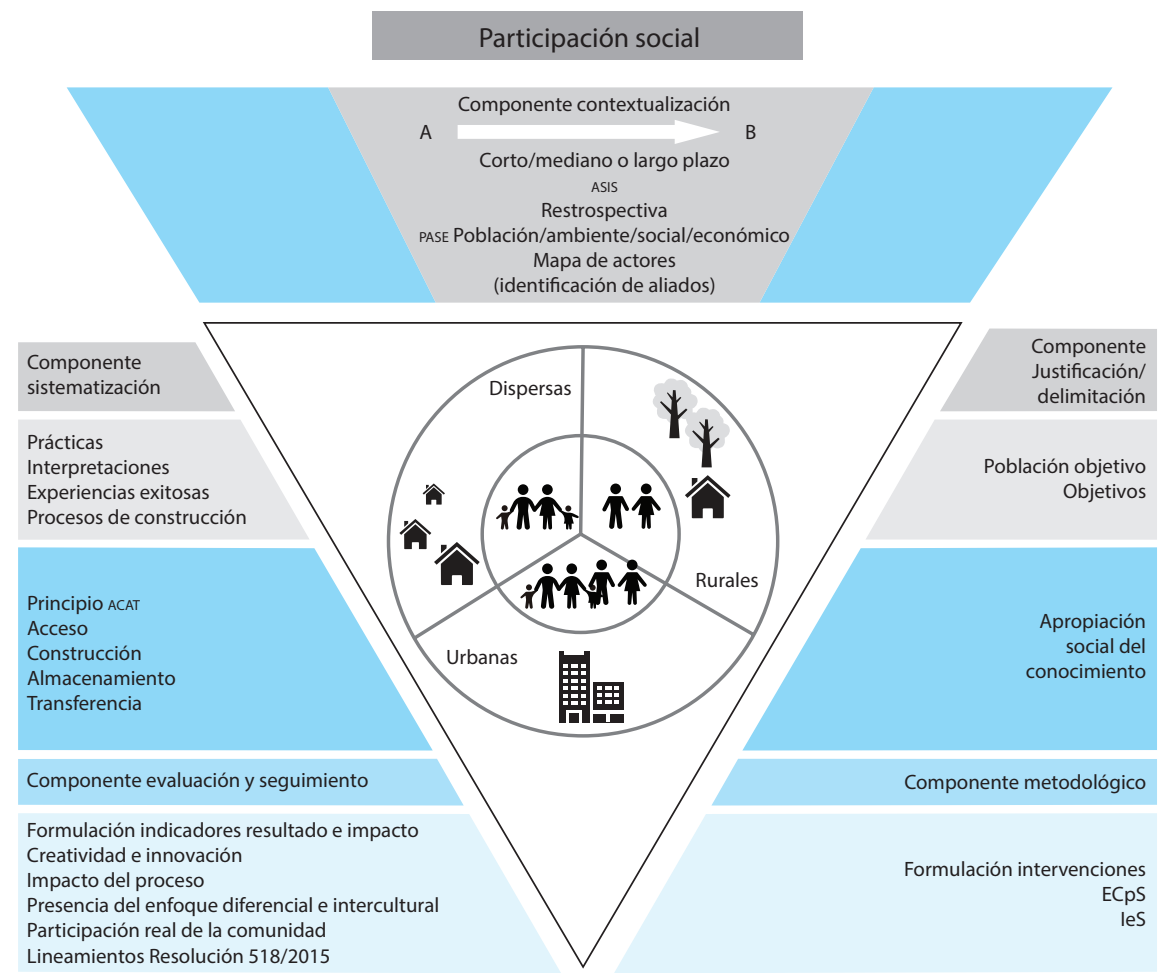

Gestión de conocimiento

Fuente: elaboración propia.

\section{A MODO DE CONCLUSIÓN}

La educación para la salud es una expresión de gobernanza del Estado hacia las comunidades y viceversa.

- Transformar el discurso en acciones es la apuesta de este proyecto, trazar un camino inexistente o poco recorrido para acercarse a un horizonte deseado en la salud pública y entretejer una red para estar interconectados con los actores clave que habitan el territorio (Pemberthy et al., 2019). Esta ha sido la inspiración para aportar desde la academia y la institucionalidad, un paso certero hacia la construcción participativa de la salud en el territorio.

- Esta investigación brinda soporte y herramientas para que la Secretaría de Salud del Cauca trabaje en pro de una eficiente inversión de los recursos en salud pública 
y permita la participación de las comunidades del Cauca, pues es a través de los procesos de apropiación social de la CTeI que se construye territorio tal como lo refiere Colciencias (2016), considerando que a partir de la cultura, la música, el folclor, la oralidad, la comunicación y la multitud de expresiones, los pueblos pueden acceder, construir, almacenar y transferir conocimientos milenarios, empíricos y circunstanciales en temas como la salud.

- La gobernanza cumple un papel importante en cuanto integra distintas formas de participación en las comunidades a fin de lograr mejores procesos con los distintos actores implicados, y además generar bases para la re-construcción del tejido social y de la paz.

Tal como lo afirma Whittingham (2010), "las limitaciones en el manejo del término, tanto desde la teoría como desde la práctica, tienen que ver con la incapacidad para reconocer, fortalecer e incorporar formas alternativas de gobernanza, no lideradas por el gobierno" (p. 233). Es por eso que pensar en la paz implica un serio ejercicio de gobernanza con todos los que hacen parte del territorio, de ahí que la política sea un arte que requiere de la armonización de todos los actores.

- Si el interés radica en la salud integral de las personas, la educación debe emerger como el elemento catalizador para promover el autocuidado y, como dice Luz Dary Carmona, asesora del Ministerio de Salud para la política de participación social, educadora popular y miembro del
Movimiento Nacional por el Derecho a la Salud y la Seguridad Social:

Como un proceso transformador, como una herramienta de poder y como una posibilidad concreta para disminuir brechas y desigualdades sociales [...] la educación además es una posibilidad de desalienar al sujeto, la educación es posibilidad de libertad, de comprensión de la vida, de ganar autonomía, cuando la gente realmente se educa tendrá que ganar mayor autonomía y mayores posibilidades de ser y de hacer. (Carmona, 2018)

- Es importante decir que el valor intrínseco de la apropiación social es altísimo, porque es el inalienable, subjetivo, requiere de una recepción activa, de una decodificación y una recodificación desde lo propio; en esa medida, es un bien incalculable para las comunidades y claramente lo han venido haciendo desde siempre. Es un elemento transversal a la hora de pensar cualquier estrategia de salud pública con las comunidades. De ahí parten el diálogo de saberes, los acuerdos, las negociaciones. Es el camino hacia el reconocimiento y la construcción.

- La relación entre capital social, participación activa y promoción de la salud se estrecha cuando de apropiación social del conocimiento en salud se habla. Esta es una de las grandes conclusiones de esta investigación puesto que la definición de apropiación social surge desde los individuos quienes hacen parte de grupos poblacionales que habitan un territorio; si ellos se empoderan lo suficiente, si son conscientes del papel que juegan en su entorno, si participan activamente en la gestión de la salud a través de la promo- 
ción y prevención, habrán logrado apropiar conocimientos para ellos desde sus cosmovisiones. Muchas de las respuestas residen y se manifiestan en ellos, y solo pueden validarse y legitimarse a través de ellos. De esa manera, el autocuidado podrá cumplir la función que Leonardo Boff define acertadamente: "la de prevención de daños futuros y regeneración de daños pasados" (citado por Arango, 2011, p. 150).

- A partir de la categoría de apropiación social se consolida un "proceso de acción social que promueve la participación de la gente, organizaciones y comunidades hacia los objetivos de lograr un mayor control individual y comunitario, eficacia política, mejoría en la calidad de vida comunitaria y justicia social" (Wallerstein, 1992, p. 6). Este proceso se denomina empoderamiento y favorece la competencia cultural de las iniciativas de promoción y, de esa forma, su real impacto y potencial sustentabilidad.

- La producción intelectual, científica y documental en cuanto al término/categoría/concepto de apropiación social del conocimiento en salud, de acuerdo con la revisión documental y bibliográfica adelantada, no es representativa. Se requiere indagar mucho más acerca de la conceptualización de su hacia otras disciplinas o áreas del conocimiento y que tengan que ver con los procesos sociales, de inmersión comunitaria y de análisis de contexto. Pese a que el concepto de apropiación social se asocia la mayoría de las veces a temas de ciencia, tecnología e innovación (CTeI), y en Colombia, específicamente, es una estrategia abanderada por Colciencias, es urgente y prioritario que se comprenda, aplique, descubra e indague desde otras aristas del conocimiento.

- Uno de los logros de esta investigación es la propuesta del principio ACAT (acceso, construcción, almacenamiento y transferencia) como método de operativización del enfoque de GC para la APs. Este principio pretende dar respuesta a un vacío conceptual y operativo/institucional que intenta resolverse a través de la guía metodológica propuesta. Para el ente territorial de salud es importante conocer cómo acceden, construyen, almacenan y transfieren los conocimientos las comunidades, información que ellas mismas requieren para seguir adaptándose al entorno, al territorio y para aportarle a la supervivencia de su cultura. La educación para la salud debe permitir, posibilitar y preparar los espacios de transformación de los datos inertes a la sabiduría de los pueblos.

- Finalmente, estas discusiones se abren camino en un contexto donde se empieza a desplazar la mirada hacia el sujeto, hacia las personas, allá donde transcurre la vida. El camino es largo, pero en la medida que las certezas empiecen a desvanecerse, seguirán surgiendo incertidumbres que labren un sendero más amplio, más participativo, entretejido con saberes, sentires y pensares. 


\section{REFERENCIA}

Arango, J. B. (2011). El ethos que cuida. Itinerario Educativo, 25(58), 145-163. Recuperado de http:// revistas.usbbog.edu.co/index.php/Itinerario/ issue/view/136

Arboleda Castrillón, T. y Daza Caicedo, S. (2016). Cuando la apropiación social de la ciencia y tecnología es objeto de gestión. Una reflexión desde el caso colombiano. Trilogía Ciencia Tecnología Sociedad, 8(15), 81-95. doi:https://doi. org/10.22430/21457778.401

Bojacá Acosta, J. (2005). El proyecto de investigación etnográfica en el aula: marco teórico-operativo. Hallazgos - Revista de Investigaciones, 2(3), 87-99. doi:10.15332/2422409X

Castiel, L. y Sanz Valero, J. (2010). El acceso a la información como determinante social de la salud. Nutrición Hospitalaria, 25(3), 26-30.

Chica, A., Ramírez, L., Cuadros, J., Lasso, J. C., Quiceno, L., Rico, E. et al. (2019). Radio Nacional de Colombia. Recuperado de https://www.radionacional.co/noticias/indigenas-colombia-conservarlenguas?fbclid=IwAR3wxjF9MLf2MarUPtic3Z UXB9y8TQ-o5KyTNBtD0tNbu2wRKfl1qvzz$\mathrm{BzM}$

Colciencias - Departamento Administrativo de Ciencia, Tecnología e Innovación. (2016). Experiencias en apropiación social de la ciencia, la tecnología y la innovación. V Foro Nacional de Apropiación Social de la Ciencia, la Tecnología y la Innovación. Trilogía Ciencia Tecnologia Sociedad, 8(15), 145-150. doi:https://doi. org/10.22430/21457778.403

Comelles, J. y Perdiguero-Gil, E. (2017). Educación, comunicación y salud:perspectivas desde las ciencias humanas y sociales. Tarragona: Publicaciones URV.
Congreso de la República (2007). Ley 1122 del 09 de enero de 2007. Por la cual se hacen algunas modificaciones en el Sistema General de Seguridad Social en Salud. Bogotá D.C.

Congreso de la República (2015). Ley estatutaria 1751 del 16 de febrero de 2015. Por medio de la cual se regula el derecho fundamental a la salud y se dictan otras disposiciones. Bogotá D.C: República de Colombia. Gobierno Nacional.

Constitución Politica de Colombia (1991). Artículo 342. Capítulo 2. Recuperado de http://www. constitucioncolombia.com/titulo-12/capitulo-2/ articulo-342

Departamento Administrativo Nacional de Estadística (DANE) (s. f.). Guía para diseño, construcción e interpretación de indicadores. Bogotá: DANE.

Departamento Nacional de Planeación (DNP) (s. f.). ¿Qué es el Plan Nacional de Desarrollo? Recuperado de https://www.dnp.gov.co/Plan-Nacional-deDesarrollo/Paginas/Qu-es-el-PND.aspx

Duarte, S., Rojas, A., Dorigo, D., Arias, F., Vega, C. y Rolón, M. (2015). Vinculando la investigación con la sociedad a través de los Living Labs. Una experiencia paraguaya. Global Journal of HumanSocial Science: Interdisciplinary, 15(8).

Escobar, J. y Jímenez, F. I. (2017). Grupos focales: una guía conceptual y metodológica. Cuadernos Hispanoamericanos de Psicología, 9, 51-67.

Falla, S., Hermelin, D. y Aguirre, C. (2016). Conectar comunidades para construir sentidos sociales en torno al conocimiento. Trilogía Ciencia Tecnología Sociedad, 8(15), 57-68. doi:https://doi. org/10.22430/21457778.400

Freire, P. (1969). La educación como práctica de la libertad. Montevideo: Tierra Nueva.

Gil, E. P. (2015). La "educación sanitaria" en el ideario médico-social del franquismo a través de la revista 
SER. Elche: Editorial de la Universidad Miguel Hernández de Elche.

Gobernación del Cauca (2016). Plan de Desarrollo Departamental: Cauca Territorio de Paz 2016-2019. Popayán: Gobernación.

Kaplún, M. (1998). Una pedagogía de la Educación. Madrid: Ediciones de La Torre.

Llanusa Ruiz, S. B., Rojo Pérez, N., Caraballoso Hernández, M., Capote, R. y Pérez Piñeros, J. (2005). Las tecnologías de información y comunicación y la gestión del conocimiento en el sector salud. Revista Cubana de Salud Pública, 31(3), 223-232.

Macías, C. (2009). La gestión del conocimiento en el área de la salud. Revista de Evidencia e Investigación Clínica, 2(1), 31-35.

Marín Agudelo, S. (2012). Apropiación social del conocimiento: una nueva dimensión de los archivos. Revista Interamericana de Bibliotecología, 35, 55-62.

Mariño, G. (2011). Sistematización de experiencias, una propuesta desde la educación popular. Recuperado de http://www.germanmarino.com/index.php/ descarga-mi-obra/2015-10-27-18-18-48

Martínez Herrera, E. (2007). La gestión del conocimiento en políticas públicas en salud y participación social. Revista CES Medicina, 21(1), 101-108. Recuperado de https://www.redalyc.org/articulo. oa? id=261120985010

Mejía Rocha, M. I. y Salgado Colín, M. (2009). Gestión del conocimiento y su importancia en las organizaciones. Revista Trilogía, (9), 25-35.

Ministerio de Salud y Protección Social (2013). MinSalud - Plan Decenalde Salud Pública 2012-2021. Recuperado de https://www.minsalud.gov.co/plandecenal/Paginas/como-se-construyo.aspx

Ministerio de Salud y Protección Social (2013). Plan Decenal de Salud Pública 2012-2021. Bogotá D.C: Imprenta Nacional de Colombia.
Ministerio de Salud y Protección Social (2014). Guía para la planificación, implementación y evaluación de la asistencia técnica en el Ministerio de Saludy Protección Social. Bogotá: MinSalud.

Ministerio de Salud y Protección Social (2015). Orientaciones para el desarrollo de la Información en salud en el marco del PIC. Bogotá: Minsalud.

Ministerio de Salud y Protección Social (2015). Resolución 518 del 2015. Por la cual se dictan las disposiciones en relación con la Gestión Pública. Bogotá D.C: Ministerio de Salud y Protección Social.

Ministerio de Salud y Protección Social (2016). Orientaciones para el desarrollo de la Educación y Comunicación para la salud en el marco del Plan de Salud Pública de Intervenciones Colectivas - PIC. Bogotá: MinSalud.

Ministerio de Salud y Protección Social (2016). Política de atención integral en salud: un sistema de salud al servicio de la gente. Bogotá: MinSalud.

Ministerio de Salud y Protección Social (2017). Directrices educación y comunicación para la salud en el marco de la implementación de las Rutas Integrales de Atención en Salud-RIAS. Bogotá: MinSalud.

Ministerio de Salud y Protección Social (2017). Resolución 2063 de 2017. Por la cual se adopta la política de Participación Social en Salud. Bogotá: MinSalud.

Neüman, M. I. (2008). Construcción de la categoría: Apropiación Social. Quórum Académico, 5(2), $67-98$

Organización Mundial de la Salud (OMS) (1989). Manual sobre educación sanitaria en atención primaria en salud. Ginebra: OMS.

Organización Panamericana de la Salud (OPS) (2000). Bases metodológicas para evaluar la viabilidad y el impacto de proyectos de telemedicina. Madrid: Universidad Politécnica de Madrid. 
Organización Panamericana de la Salud (ops) (2012). Mujeres parteras del Pacifico caucano colombiano cuentan con el apoyo de OPS, OIM y USAID. Recuperado de https://www.paho.org/col/index. php?option=com_content $\&$ view $=$ article $\& i d=$ 1199:mujeres-parteras-del-pacifico-caucanocolombiano-cuentan-con-el-apoyo-de-ops-oimy-usaid\&Itemid $=442$

Pemberthy Gallo, L. S. y Plazas Tenorio, A. (2014). Dinámica Universidad-Empresa-Estado: un esfuerzo de colaboración para encaminar la innovación abierta en el Cauca. En I. Hernández Arteaga y L. S. Pemberthy Gallo (eds.), Universidad-EmpresaEstado: hacia la cultura de la investigación y la innovación (pp. 3-22). Bogotá: Editorial Universidad Cooperativa de Colombia - Red UReL.

Pemberthy Gallo, L. S., Cruz Pino, V. P. y Viveros Palacios, V. (2019). Red de actores para impulsar el desarrollo cultural, socioeconómico y turístico de Silvia, Cauca. En S. L. Bolaños Delgado y C. M. Solarte Solarte (eds.). Factores determinantes de los procesos (p. 447). San Juan de Pasto: Editorial Cesmag. doi:10.15658/CESMAG19.10160109

Pemberthy Gallo, L. S., Viveros Palacios, V. y Cruz Pino, V. P. (2019). Dinámicas UEES y procesos de apropiación del conocimiento para impulsar la actividad turística en Silvia, Cauca. En S. L. Bolaños Delgado y C. M. Solarte Solarte (eds.), Factores determinantes (p. 447). San Juan de Pasto: Editorial Cesmag. doi:10.15658/CESMAG19.10160109

Programa de las Naciones Unidas para el Desarrollo (PNUD) (2015). Objetivos de Desarrollo Sostenible. Recuperado de https://www.undp.org/content/undp/es/home/sustainable-developmentgoals.html

Rincón, J. J. (2009). Diversos y comunes: elementos constitutivos del conflicto entre comunidades indígenas, campesinas y afrocolombianas en el departamento del Cauca. Análisis Político, 22(65), 53-93. Recuperado de https://revistas.unal.edu. co/index.php/anpol/article/view/45959/47515

Rodríguez, M. L. (2013). Guía de Tesis: acerca de la investigación bibliográfica y documental. Recuperado de https:/guiadetesis.wordpress.com/2013/08/19/ acerca-de-la-investigacion-bibliografica-y-documental/

Universidad del Rosario (s. f.). Investigación en Derecho Ambiental. Recuperado de https://www. urosario.edu.co/jurisprudencia/catedra-vivaintercultural/ur/La-Consulta-Previa/Que-es-laConsulta-Previa/

Unidad para la Atención y Reparación Integral a las Víctimas (UARIV) (2019). Recuperado de https:// www.unidadvictimas.gov.co/es/reparacion/caucaatiende-cada-mes-19-mil-victimas-del-conflictoarmado/47033

Valadez Figueroa, I., González Álvarez, J. A., Vargas Valadez, V., Alfaro Alfaro, N., Fausto Guerra, J., Luevanos Velázquez, A. et al. (2016). La educación para la salud en procesos de intervención participativa. Guadalajara: Editorial Secretaría de Cultura de Jalisco.

Victoria, P. A., Pemberthy, L. S. y Maya, N. C. (2007). Knowledge management: A key factor for productive chain evolution in the department of Cauca, Colombia. A case study of the fishing chain network. Knowledge Management for Development Journal, 3, 95-104. Recuperado de https://www. researchgate.net/publication/334545883

Wallerstein, N. (1992). Powerlessness, empowerment, and health: implications for health promotion programs. American Journal of Health Promotion, 6(3), 197-205.

Whittingham, M. V. (2010). ¿Qué es la gobernanza y para qué sirve? Revista Análisis Internacional, (2), 219-235. 


\section{Entrevistas}

Buenos Aires, C. (2017). Grupo Focal para la caracterización de las dinámicas de gestión de conocimiento para la apropiación social en los procesos de información, educación y comunicación (M. A. Cisneros, entrevistador).

Carabalí, O. (2017). Grupo focal con parteras del municipio de Buenos Aires - Cauca (M. A. Cisneros, entrevistador).

Carabalí, T. (2017). Grupo focal con parteras de Buenos Aires - Cauca (M. A. Cisneros, entrevistador).

Carmona, L. D. (2018). Asesora del Ministerio de Salud para la política de participación social (M. A. Cisneros, entrevistador).
El Tambo (2017). Grupo Focal para la caracterización de las dinámicas de gestión de conocimiento para la apropiación social en los procesos de información, educación y comunicación (M. A. Cisneros, entrevistador).

Mamadominga (2018). Entrevista para caracterizar las dinámicas de gestión de conocimiento para la apropiación social en los procesos de información, educación y comunicación (IEC) desde el pueblo misak (M. A. Cisneros, entrevistador). 